\title{
EVALUASI WEBSITE KULIAH ONLINE STMIK AMIKOM PURWOKERTO MENGGUNAKAN METODE HEURISTIK (STUDI KASUS MATA KULIAH ENTERPRISE RESOURCE MANAGEMENT)
}

\author{
Debby Ummul Hidayah ${ }^{1}$, Ika Romadoni Yunita ${ }^{2}$, Gustin Setyaningsih ${ }^{3}$ \\ 1,2,3 Jl. Letjen Pol Sumarto Watumas Purwanegara Purwokerto, Banyumas 53123 \\ 1Email : debbyummul@amikompurwokerto.ac.id, 2ikarom@amikompurwokerto.ac.id, \\ ${ }^{3}$ gustin@amikompurwokerto.ac.id
}

\begin{abstract}
ABSTRAK
Kuliah online menjadi salah satu alternatif untuk mendukung perkuliahan jarak jauh. STMIK Amikom Purwokerto telah menerapkan sistem perkuliah online tersebut. Guna mendukung pembelajaran yang efektif saat kuliah online menggunakan media website maka diperlukan antarmuka web yang efektif. Namun, ditemukan beberapa keluhan dari para pengguna saat mengakses web kuliah online. Salah satunya pengguna belum memahami secara keseluruhan penggunaan fungsi pada sistem yang ada. Oleh sebab itu diperlukan evaluasi heuristik guna mengetahui seberapa tingkat usability pada sistem dalam mendukung kuliah online. Hasilnya menunjukkan bahwa berdasarkan hasil perhitungan menggunakan evaluasi heuristik didapatkan nilai severety rating dengan skala 3 yang berarti website kuliah online di STMIK Amikom Purwokerto perlu adanya perbaikan secara menyeluruh baik dari fungsionalitas sistem maupun desain antarmuka.
\end{abstract}

Keyword : Evaluasi, kuliah online, metode heuristik

\begin{abstract}
Online lecture is one alternative to support distance learning. STMIK Amikom Purwokerto has implemented the online lecture system. In order to support effective learning while studying online using website media, an effective web interface is needed. However, there were complaints from users when accessing web lectures online. One of them is the user does not understand the overall use of functions on the existing system. Therefore heuristic evaluation is needed to find out how useful the system is in supporting online lectures. The results show that based on the calculation results using heuristic evaluation, the severety rating with a scale of 3 means that the online learning website at STMIK Amikom Purwokerto needs to be throughly improved from both system functionality and interface design.
\end{abstract}

Keyword: Evaluation, online lecture, heuristic method

\section{PENDAHULUAN}

Dewasa ini perkembangan teknologi informasi telah mengubah paradigma pada berbagai bidang. Tak terkecuali adalah bidang pendidikan. Dalam bidang pendidikan, teknologi berperan sebagai salah satu pendukung kegiatan pembelajaran. Salah satu penerapannya adalah kuliah online.

Menurut Undang-Undang Nomor 12 Tahun 2012 Pasal 1 menjelaskan bahwa "pendidikan adalah usaha sadar dan terencana untuk mewujudkan suasana belajar dan proses pembelajaran agar peserta didik secara aktif mengembangkan potensi dirinya untuk memiliki kekuatan spiritual keagamaan, pengendalian diri, kepribadian, kecerdasan, akhlak mulia, serta keterampilan yang diperlukan dirinya, masyarakat, bangsa, dan negara" [1]. Berdasarkan pengertian tersebut dapat diketahui bahwa proses pendidikan membuka peluang bagi para peserta didiknya untuk membuka pikiran dengan cara mengenal potensi diri dan berupaya untuk mengembangkannya.

Salah satu wujud pendidikan adalah pengajaran. Pengajaran berarti memberikan ilmu pengetahuan kepada para peserta didik. Dosen mengajar mahasiswa agar mahasiswa memperoleh ilmu pengetahuan[2].

Seiring dengan pesatnya teknologi, metode mengajar saat ini tidak terbatas secara tatap muka saja. Tetapi sudah menawarkan mekanisme baru yaitu kuliah secara online. Jika dalam pengajaran tidak ada pembaruan dalam mengikuti perkembangkan zaman, maka metode pengajaran yang ada sebelumnya menjadi usang [3].

Kuliah online merupakan metode pembelajaran dengan memanfaatkan media teknologi informasi dan komunikasi berupa internet [4]. Definisi lainnya menurut Barbara dalam [5] kuliah online merupakan salah satu 
metode penyampaian materi secara digital untuk memberikan kemudahan dalam layanan pembelajaran. Dengan demikian peserta didik dapat belajar di manapun dan kapanpun menggunakan piranti komputer/laptop selama terkoneksi dengan jaringan internet . Dalam menjalankan proses pembelajarannya, kampus STMIK Amikom Purwokerto telah menerapkan sistem kuliah online. Sistem tersebut dapat diakses melalui alamat www.kuliahonline. amikompurwokerto. ac.id. Penerapan sistem kuliah online tersebut telah dilakukan sejak semester ganjil 2017/2018. Media yang digunakan masih bebas. Dosen bisa menggunakan media seperti whatsapp, edmodo, facebook, atau media online lainnya. Kemudian menginjak semester genap 2017/2018, media yang digunakan beralih menggunakan berbasis website yang dikhususkan untuk menunjang kuliah online.

Kuliah online tersebut berisi sekumpulan grup diskusi yang merupakan wadah untuk melakukan aktivitas diskusi yang tersambung dengan koneksi internet. Dengan demikian mahasiswa hanya memilih grup diskusi kelasnya saja [6].

Penerapan kuliah online ini telah diimplementasikan pada seluruh matakuliah salah satunya adalah ERM (Enterprise Resource Management). Matakuliah ini memiliki bobot sks yang cukup tinggi yaitu 4 sks dan bersifat teori. Oleh sebab itu penyampaian materi pada saat kuliah online perlu dipertimbangkan dengan baik.

Guna mendukung pembelajaran yang efektif saat kuliah online menggunakan media website maka diperlukan antarmuka web yang efektif. Hal ini menunjukkan bahwa web yang digunakan dapat mudah dipahami oleh pengguna. Seperti terdapat fitur untuk mengunduh materi perkuliahan, mendukung diskusi, mengunggah berkas seperti gambar atau file lain yang diperlukan, dan dapat mendukung untuk VC (Video Call). Selain itu kontrol menu harus mudah dipahami pengguna, sehingga pengguna tidak merasa kesulitan saat menggunakan web kuliah online tersebut. Tutorial atau panduan penggunaan web kuliah online pun harus ada.

Dalam perspektif interaksi manusia dan komputer, kuliah online perlu disuguhkan dengan melihat beberapa aspek penting. Pertama, pengguna perlu memahami bagaimana cara untuk menyelesaikan aktivitas tertentu dengan bantuan komputer. Kedua, pengguna perlu memahami bahwa piranti komputer tersebut dapat mendukung untuk meningkatkan pengetahuan dan keterampilan individu masingmasing [7].

Berdasarkan wawancara yang dilakukan dengan beberapa mahasiswa terkait web kuliah online STMIK Amikom Purwokerto ternyata web tersebut masih sukar untuk dipahami dan digunakan, mahasiswa masih merasa kebingungan saat menggunakan webnya terutama seperti menu-menu yang ada pada web, kemudian fitur untuk memberikan komentar yang terkadang tertutup oleh komentar lain sehingga harus mencarinya satu per satu.

Untuk membangun kuliah online yang efektif dibutuhkan interaksi yang baik antara manusia dengan sistem. Pengalaman pengguna menjadi salah satu faktor yang berpengaruh karena perspektif pengguna dapat menentukan apakah sistem yang dibangun mudah digunakan atau sebaliknya. Dalam hal ini, konsep HCI atau human computer interaction perlu diperhatikan. Sebab peran utama dari HCI inilah yang mampu berperan untuk membangun sistem yang aman, berguna, efektif, dan efisien [8].

Pada penelitian sebelumnya, pernah dilakukan oleh [9] tentang evaluasi web based learning menggunakan metode evaluasi heuristik di RMIK STIKES Yayasan RS Dr.Soetomo. Pada penelitian tersebut dilakukan evaluasi pada antar muka dari aplikasi web based learning try out uji kompetensi rekam medik dan informasi kesehatan. Dalam penelitian ini menyebutkan bahwa pengguna sering melihat mutu sistem hanya dengan melihat dari sistem tersebut, sehingga perlu dilakukan evaluasi heuristik. Hasilnya menunjukkan bahwa sistem tersebut masuk dalam kategori mudah digunakan. Penelitian serupa juga pernah dilakukan oleh [10] tentang evaluasi heuristik pada web based learning. Hasilnya menunjukkan bahwa web learning tersebut dikatakan mudah digunakan dengan nilai usability sebesar $10 \%$.

Dari kedua penelitian tersebut dapat diambil kesimpulan bahwa evaluasi heuristik merupakan salah satu metode yang dapat digunakan untuk mengukur sejauh mana tingkat kebergunaan/usability desain antarmuka. Dengan mengetahui permasalahan pada sistemnya, diharapkan dapat diperbaiki menurut 
standar yang ada. Metode evaluasi heuristik menjadi salah satu metode yang cukup efektif untuk memperbaiki desain sistem yang berfokus pada desain antarmuka[11].

Berdasarkan uraian permasalahan di atas maka peneliti tertarik untuk menganalisis dan mengevaluasi desain web kuliah online dalam mendukung kegiatan pembelajaran. Metode yang digunakan untuk mengevaluasi desain web kuliah online menggunakan metode heuristik dengan melihat aspek usability. Hasil dari evaluasi ini diharapkan dapat menjadi solusi guna perbaikan web kuliah online kedepannya. Sehingga kuliah online dapat berjalan dengan baik dan mahasiswa tidak merasa kesulitan untuk menggunakan fitur-fitur pada web kuliah online.

\section{METODOLOGI}

\section{Populasi dan Sampel Penelitian}

Populasi dalam penelitian ini merupakan pengguna sistem web kuliah online pada mata kuliah ERM, yaitu mahasiswa prodi Sistem Informasi (SI) semester 3 tahun ajaran 20182019 kelas SI2017 A, SI2017 B, dan SI2017 C. Sedangkan sampel dalam penelitian ini menggunakan teknik nonprobability sampling yaitu teknik pengambilan sampel dengan tidak memberikan peluang yang sama pada anggota populasi yang nantinya akan dipilih menjadi sampel. Sedangkan penentuan sampelnya menggunakan teknik sampling insidental yaitu teknik untuk menentukan jumlah sampel berdasarkan kebetulan. Jadi siapa saja yang secara kebetulan bertemu dengan peneliti dapat digunakan untuk sampel. Akan tetapi orang yang bersangkutan dipandang cukup layak untuk dijadikan sebagai sumber data [12].

\section{Metode Pengumpulan Data}

Pengumpulan data primer diperoleh dengan melakukan penyebaran kuisioner. Adapun penilaiannya menggunakan ukuran skala likert yang diukur dari $1 \mathrm{~s} / \mathrm{d} 5$. Menurut Sugiyono dalam [13] skala likert merupakan skala pengukuran untuk mengukur sikap, pendapat, dan persepsi seseorang atau kelompok tentang fenomena sosial.

Tabel 1. Tabel Nilai

\begin{tabular}{|c|c|c|c|c|c|}
\hline PK & KBS & KB & CB & B & SB \\
\hline Nilai & 1 & 2 & 3 & 4 & 5 \\
\hline
\end{tabular}

Keterangan:

$\begin{array}{ll}\mathrm{PK} & =\text { Pernyataan Kuisioner } \\ \mathrm{KBS} & =\text { Kurang Baik Sekali } \\ \mathrm{KB} & =\text { Kurang Baik } \\ \mathrm{CB} & =\text { Cukup Baik } \\ \mathrm{B} & =\text { Baik } \\ \mathrm{SB} & =\text { Sangat Baik }\end{array}$

10 Aspek Evaluasi Heuristik

1. Visibilitas Status Sistem

Sistem yang baik harus mampu memberikan informasi kepada para user mengenai apa yang sedang terjadi saat ini melalui suatu pesan yang baik dan waktu yang tepat.

2. Kecocokan antara sistem dan dunia nyata

Sistem mampu berbicara dengan bahasa user. Seperti penggunaan kata, kalimat, atau suatu konsep yang biasa dipakai oleh user.

3. Kontrol user dan kebebasan

Dalam hal ini para pengguna merasa bebas untuk memilih atau melakukan suatu pekerjaan yang disesuaikan kebutuhan. Pengguna harus mampu mengambil keputusan tentang apa yang dia lakukan. Selain itu sistem juga harus mampu melakukan undo atau redo.

4. Konsistensi dan standar

Suatu user interface dapat dikatakan memiliki ciri-ciri yang konsisten apabila desain antarmuka sistem mampu menghindarkan user dari rasa was-was atau ragu-ragu di saat memakai atau mengoperasikan sistem.

\section{Pengecegahan kesalahan}

Sistem yang baik tentunya mampu membuat pengguna untuk menghindari segala kesalahan. Oleh sebab itu pencegahan kesalahan pada sistem perlu diperhatikan.

6. Pengenalan atas penarikan kembali

User tidak bertanya kembali tentang perbedaan pemahaman pada suatu kata, kalimat, situasi, maupun aksi.

7. Fleksibilitas dan efisiensi

Dalam hal ini suatu sistem mampu menjadi akomodasi bagi user yang ahli atau profesional dan user pemula. Sehingga perlu adanya alternatif untuk kategori pengguna yang berbeda tersebut.

8. Berhubungan dengan keindahan dan desain minimalis 
Sistem harus mampu menghasilkan informasi yang relevan.

9. Bantuan bagi user untuk mengenali, mendiagnosis, dan memperbaiki dari kesalahan

\section{Help dan Dokumentasi}

Sistem yang baik seharusnya memiliki suatu pedoman bagaimana menggunakan sistem tersebut. Karena pengguna dapat mempelajari sistem tersebut dengan lebih cepat serta mudah.

Gambar 1 merupakan flowchat yang menunjukkan urutan atau langkah-langkah penelitian.

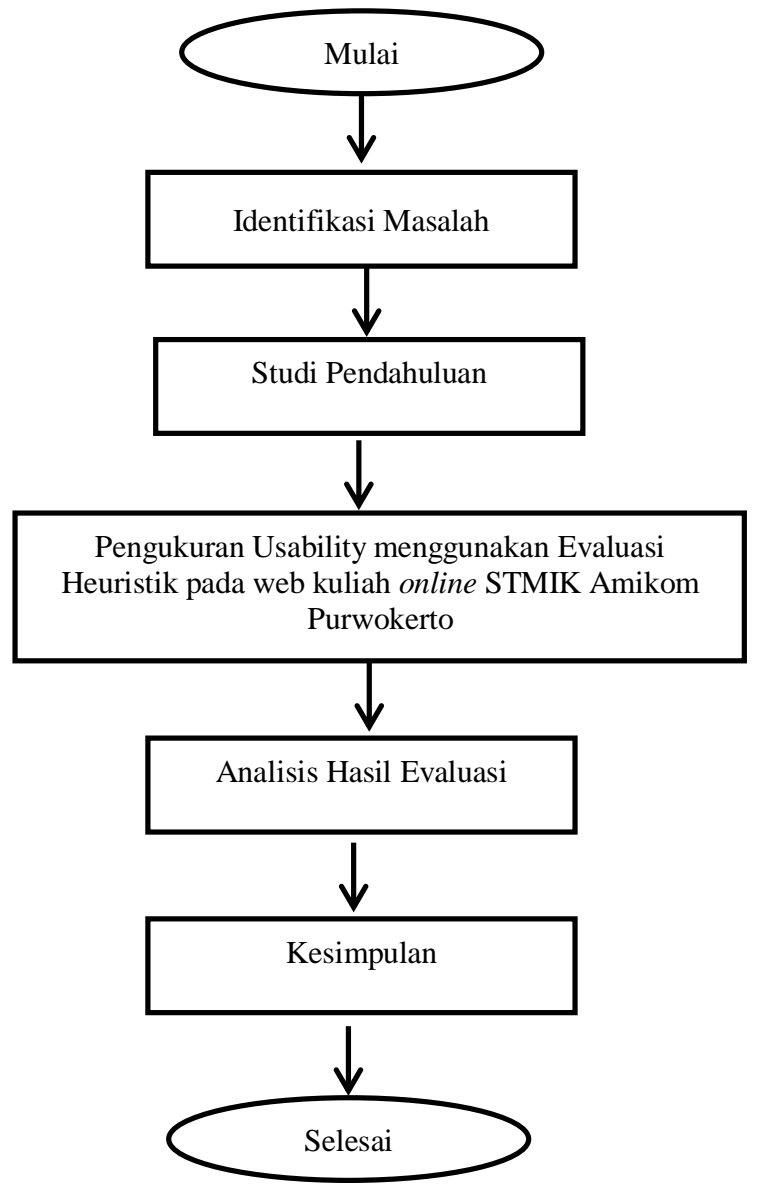

Gambar 1. Flowchart alur penelitian [14]

Penelitian ini termasuk jenis penelitian kualitatif yaitu suatu penelitian yang data utamanya bukan suatu angka, akan tetapi datadata tersebut seperti hasil survei, opini, dan lain-lain. Data-data tersebut kemudian direpresentasikan menjadi angka lalu diolah secara sistematis untuk kemudian diambil suatu kesimpulan dan menjadi solusi dari permasalahan yang diteliti [15]. Adapun desain penelitian ini dapat digambarkan seperti pada gambar 1.

Proses dan tahapan yang dilakukan dalam penelitian ini dimulai dari mengidentifikasi masalah. Kemudian dilanjutkan dengan studi pendahuluan. Dalam studi pendahuluan ini peneliti mencari literatur terkait penelitian dan mengamati objek yang diamati yaitu web kuliah online STMIK Amikom Purwokerto. Pencarian literatur berguna untuk melakukan pencarian referensi dan informasi pendukung untuk memperkuat kajian penelitian yang dilakukan. Selanjutnya dilakukan pengukuran web kuliah online STMIK Amikom Purwokerto menggunakan metode evaluasi heuristik dengan menyebarkan kuesioner. Kemudian dilakukan rekapitulasi dan perhitungan hasil rata-rata nilai uji atas web kuliah online dan diakhiri dengan penarikan kesimpulan. Penarikan kesimpulan akan dirumuskan setelah semua prosedur penelitian dilaksanakan.

\section{HASIL DAN PEMBAHASAN}

Tampilan halaman web kuliah online yang akan dievaluasi salah satunya seperti terdapat pada gambar 2,3,4, dan 5 .

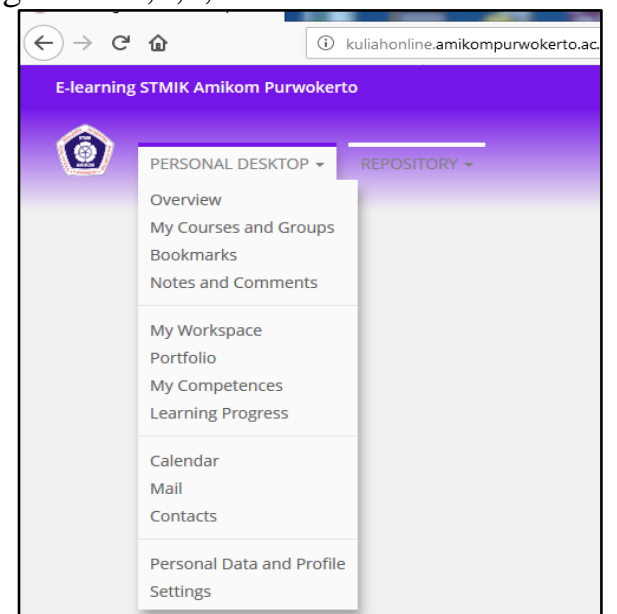

Gambar 2. Menu halaman web kuliah online

Mail क

ADMIN E-LEARNING STMIK AMIKOM PURWOKERTO

buddy_notification_contact_request ADMIN E-LEARNING STMIK AMIKOM PURWOKERTO

buddy_notification_contact_request

ADMIN E-LEARNING STMIK AMIKOM PURWOKERTO

buddy_notification_contact_request ADMIN E-LEARNING STMIK AMIKOM PURWOKERTO

buddy_notification_contact_request ADMIN E-LEARNING STMIK AMIKOM PURWOKERTO

buddy_notification_contact_request 
Gambar 3. Notifikasi pesan masuk pada web kuliah online

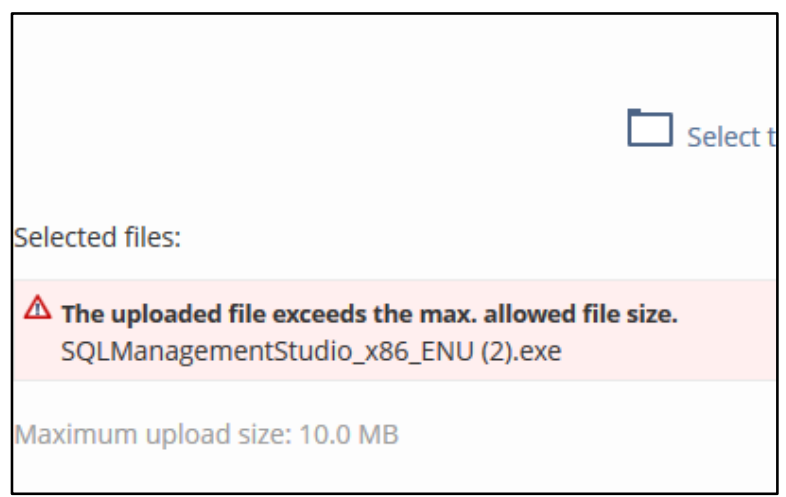

Gambar 4. Pesan kesalahan error saat mengunggah file melebihi kapasitas maksimum

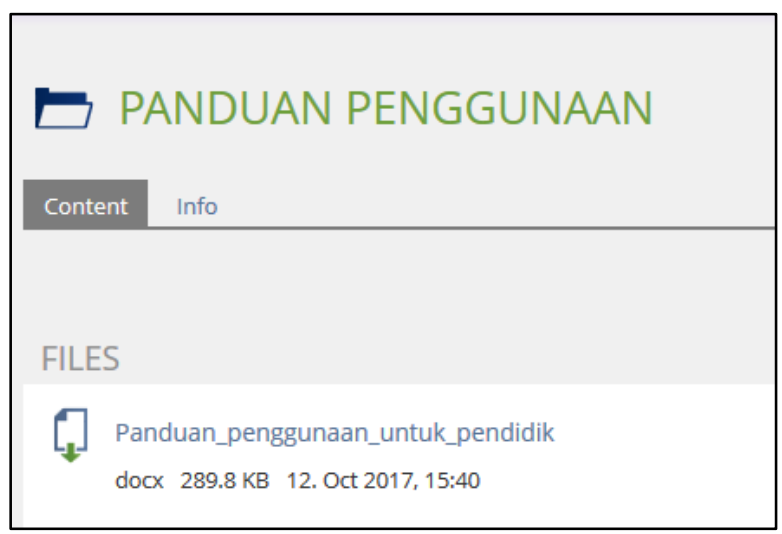

Gambar 5. Panduan penggunaan web kuliah online masih terbatas untuk pendidik saja

Tabel 2. Plot Aspek Evaluasi Heuristik dan Sub Aspek Evaluasi Heuristik

\begin{tabular}{|c|l|ll|}
\hline Kode & \multicolumn{1}{|c|}{ Aspek } & \multicolumn{2}{|c|}{$\begin{array}{l}\text { Sub-Aspek Evaluasi } \\
\text { Heuristik }\end{array}$} \\
\hline & Visibilitas & 1. & $\begin{array}{l}\text { Kejelasan informasi } \\
\text { yang ditampilkan } \\
\text { status sistem }\end{array}$ \\
$\mathrm{H}_{1}$ & & $\begin{array}{l}\text { Web kuliah online } \\
\text { Kesesuaian waktu } \\
\text { akses web kuliah } \\
\text { online } \\
\text { Konsistensi tampilan } \\
\text { web kuliah online }\end{array}$ \\
\hline $\mathrm{H}_{2}$ & $\begin{array}{l}\text { Kecocokan } \\
\text { antara sistem } \\
\text { dan dunia } \\
\text { nyata }\end{array}$ & $\begin{array}{l}\text { 1. } \\
\text { Terminologi menu } \\
\text { dan halaman web } \\
\text { yang komunikatif } \\
\text { 2. }\end{array}$ & $\begin{array}{l}\text { Penggunaan gambar } \\
\text { yang komunikatif } \\
\text { 3emilihan warna } \\
\text { web kuliah online } \\
\text { Penggunaan tata }\end{array}$ \\
& & 4.
\end{tabular}

\begin{tabular}{|c|c|c|}
\hline & & $\begin{array}{l}\text { bahasa dalam web } \\
\text { kuliah online }\end{array}$ \\
\hline $\mathrm{H}_{3}$ & $\begin{array}{l}\text { Kontrol user } \\
\text { dan kebebasan }\end{array}$ & $\begin{array}{l}\text { 1. Kemudahan navigasi } \\
\text { 2. Pembatalan sebuah } \\
\text { operasi }\end{array}$ \\
\hline $\mathrm{H}_{4}$ & $\begin{array}{l}\text { Konsistensi } \\
\text { dan standar }\end{array}$ & $\begin{array}{l}\text { 1. Konsistensi standar } \\
\text { penulisan pada web } \\
\text { kuliah online } \\
\text { 2. Konsistensi data dan } \\
\text { proses menginput } \\
\text { data pada web kuliah } \\
\text { online }\end{array}$ \\
\hline $\mathrm{H}_{5}$ & $\begin{array}{l}\text { Pencegahan } \\
\text { kesalahan }\end{array}$ & $\begin{array}{l}\text { 1. Notifikasi jika ada } \\
\text { pesan masuk } \\
\text { 2. Pencegahan } \\
\text { penggunaan dalam } \\
\text { membuat kesalahan }\end{array}$ \\
\hline $\mathrm{H}_{6}$ & $\begin{array}{l}\text { Pengenalan } \\
\text { atas penarikan } \\
\text { kembali }\end{array}$ & $\begin{array}{l}\text { 1. } \begin{array}{l}\text { Adanya keterangan } \\
\text { pada setiap tombol }\end{array} \\
\text { pada web kuliah } \\
\text { online } \\
\text { 2. Kejelasan } \\
\text { penggunaan bahasa } \\
\text { simbol dan gambar } \\
\text { pada web kuliah } \\
\text { online } \\
\text { 3. Adanya pesan } \\
\text { kesalahan jika terjadi } \\
\text { error }\end{array}$ \\
\hline $\mathrm{H}_{7}$ & $\begin{array}{l}\text { Fleksibilitas } \\
\text { dan efisiensi }\end{array}$ & $\begin{array}{lrr}\text { Sistem } & \text { web } & \text { kuliah } \\
\text { online } & \text { sesuai } & \text { dengan } \\
\text { screen reading } & \end{array}$ \\
\hline $\mathrm{H}_{8}$ & $\begin{array}{l}\text { Berhubungan } \\
\text { dengan } \\
\text { keindahan dan } \\
\text { desain } \\
\text { minimalis }\end{array}$ & $\begin{array}{l}\text { 1. Desain web kuliah } \\
\text { online interaktif } \\
\text { 2. Pemilihan warna } \\
\text { font dan backround } \\
\text { pada web kuliah } \\
\text { online } \\
\text { 3. Ukutan font pada } \\
\text { pengisian kotak } \\
\text { dialog } \\
\text { 4. Pengelompokkan } \\
\text { informasi } \\
\text { berdasarkan tipe } \\
\text { mata kuliah }\end{array}$ \\
\hline $\mathrm{H}_{9}$ & $\begin{array}{l}\text { Bantuan bagi } \\
\text { user untuk } \\
\text { mengenali, } \\
\text { mendiagnosis } \\
\text { dan } \\
\text { memperbaiki } \\
\text { kesalahan }\end{array}$ & $\begin{array}{l}\text { 1. Notifikasi jika ada } \\
\text { kesalahan } \\
\text { 2. Repairing system }\end{array}$ \\
\hline $\mathrm{H}_{10}$ & $\begin{array}{l}\text { Help dan } \\
\text { dokumentasi }\end{array}$ & $\begin{array}{l}\text { 1. Bantuan saat adanya } \\
\text { pesan kesalahan }\end{array}$ \\
\hline
\end{tabular}




\begin{tabular}{|l|l|l|}
\hline & $\begin{array}{l}\text { 2. } \\
\begin{array}{l}\text { Panduan secara } \\
\text { online penggunaan } \\
\text { web kuliah online }\end{array}\end{array}$ \\
\hline
\end{tabular}

Nilai evaluasi heuristik didapatkan dengan melakukan perhitungan berdasarkan pada Tabel 2. Perhitungan pada evaluasi heuristik menggunakan persamaan (1):

$\sum H x=0 * x+1 * x+2 * x+3 * x+4 * x$

Keterangan,

$\sum H x=$ jumlah skor rating dari sub-aspek heuristik dalam setiap aspek heuristik $(\mathrm{H} 1, \mathrm{H} 2$, H10);

$x=$ poin usability, bernilai $1 / 0$

Kemudian untuk menghasilkan nilai severity rating dari tiap aspek heuristik menggunakan persamaan (2):

$S v=$

$\sum \frac{H x}{n}$

\section{Keterangan,}

$S v=$ hasil severity rating dalam satu aspek heuristik;

$n$ = banyaknya sub-aspek heuristik dalam setiap aspek heuristik

Setelah melakukan penyebaran kuesioner maka langkah selanjutnya adalah menghitung nilai hasil evaluasi heuristik menggunakan persamaan 1 dan 2. Perhitungan dari evaluasi heuristik dapat dilihat pada tabel 3 sampai tabel 12 berikut.

Tabel 3. Hitung Evaluasi Heuristik Aspek H1

\begin{tabular}{|c|c|c|c|c|c|c|c|c|}
\hline \multirow{2}{*}{$\begin{array}{c}\text { Aspek } \\
\text { Heuristik }\end{array}$} & \multirow{2}{*}{$\begin{array}{c}\text { Sub Aspek } \\
\text { Heuristik }\end{array}$} & \multicolumn{5}{|c|}{ SR } & \multirow{2}{*}{$\begin{array}{c}\text { Jumlah } \\
\text { SR }\end{array}$} & \multirow{2}{*}{ Nilai SR } \\
\hline & & 0 & 1 & 2 & 3 & 4 & & \\
\hline (A) & (B) & (C) & (D) & (E) & (F) & (G) & (I) & (J) \\
\hline \multirow[t]{5}{*}{1} & 1 & 0 & 0 & 0 & 4 & 1 & 16 & 3,2 \\
\hline & 2 & 0 & 0 & 0 & 4 & 1 & 16 & 3,2 \\
\hline & 3 & 0 & 0 & 1 & 3 & 1 & 15 & 3 \\
\hline & & 0 & 0 & 1 & 11 & 3 & & 9,4 \\
\hline & & 0 & 0 & 2 & 33 & 12 & 3 & 3,13 \\
\hline
\end{tabular}

Tabel 3 di atas merupakan rekapitulasi hasil perhitungan heuristik aspek $\mathrm{H} 1$ dengan 3 sub aspek heuristik. Nilai severety rating yang dihasilkan sebesar 3,13.

Tabel 4. Menghitung Evaluasi Heuristik Aspek H2

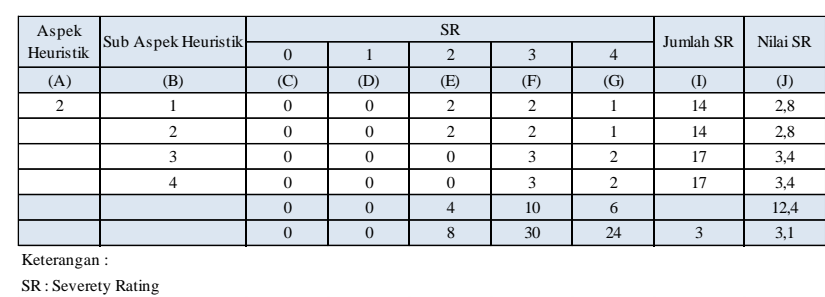

Tabel 4 di atas merupakan rekapitulasi hasil perhitungan heuristik aspek $\mathrm{H} 2$ dengan 4 sub aspek heuristik. Nilai severety rating yang dihasilkan sebesar 3,1.

Tabel 5. Menghitung Evaluasi Heuristik Aspek H3

\begin{tabular}{|c|c|c|c|c|c|c|c|c|}
\hline \multirow{2}{*}{$\begin{array}{c}\text { Aspek } \\
\text { Heuristik } \\
\end{array}$} & \multirow{2}{*}{$\begin{array}{c}\text { Sub Aspek } \\
\text { Heuristik }\end{array}$} & \multicolumn{5}{|c|}{ SR } & \multirow{2}{*}{$\begin{array}{c}\text { Jumlah } \\
\text { SR }\end{array}$} & \multirow{2}{*}{ Nilai SR } \\
\hline & & 0 & 1 & 2 & 3 & 4 & & \\
\hline (A) & (B) & (C) & (D) & (E) & (F) & (G) & (I) & (J) \\
\hline \multirow[t]{4}{*}{3} & 1 & 0 & 0 & 2 & 2 & 1 & 14 & 2,8 \\
\hline & 2 & 0 & 0 & 3 & 1 & 1 & 13 & 2,6 \\
\hline & & 0 & 0 & 5 & 3 & 2 & & 5,4 \\
\hline & & 0 & 0 & 10 & 9 & 8 & 3 & 2,7 \\
\hline
\end{tabular}

Tabel 5 di atas merupakan rekapitulasi hasil perhitungan heuristik aspek $\mathrm{H} 3$ dengan 2 sub aspek heuristik. Nilai severety rating yang dihasilkan sebesar 2,7.

Tabel 6. Menghitung Evaluasi Heuristik Aspek H4

\begin{tabular}{|c|c|c|c|c|c|c|c|c|}
\hline \multirow{2}{*}{$\begin{array}{c}\text { Aspek } \\
\text { Heuristik }\end{array}$} & \multirow{2}{*}{$\begin{array}{c}\text { Sub Aspek } \\
\text { Heuristik }\end{array}$} & \multicolumn{5}{|c|}{ SR } & \multirow{2}{*}{$\begin{array}{c}\text { Jumlah } \\
\text { SR }\end{array}$} & \multirow{2}{*}{ Nilai SR } \\
\hline & & 0 & 1 & 2 & 3 & 4 & & \\
\hline (A) & (B) & (C) & (D) & (E) & (F) & (G) & (I) & (J) \\
\hline \multirow{4}{*}{4} & 1 & 0 & 0 & 1 & 3 & 1 & 15 & 3 \\
\hline & 2 & 0 & 0 & 0 & 4 & 1 & 16 & 3,2 \\
\hline & & 0 & 0 & 1 & 7 & 2 & & 6,2 \\
\hline & & 0 & 0 & 2 & 21 & 8 & 3 & 3,1 \\
\hline
\end{tabular}

Tabel 6 di atas merupakan rekapitulasi hasil perhitungan heuristik aspek $\mathrm{H} 4$ dengan 2 sub aspek heuristik. Nilai severety rating yang dihasilkan sebesar 3,1.

Tabel 7. Menghitung Evaluasi Heuristik Aspek H5

\begin{tabular}{|c|c|c|c|c|c|c|c|c|}
\hline \multirow{2}{*}{$\begin{array}{c}\text { Aspek } \\
\text { Heuristik }\end{array}$} & \multirow{2}{*}{$\begin{array}{c}\text { Sub Aspek } \\
\text { Heuristik }\end{array}$} & \multicolumn{5}{|c|}{ SR } & \multirow{2}{*}{$\begin{array}{c}\text { Jumlah } \\
\text { SR }\end{array}$} & \multirow{2}{*}{ Nilai SR } \\
\hline & & 0 & 1 & 2 & 3 & 4 & & \\
\hline (A) & (B) & (C) & (D) & (E) & (F) & (G) & (I) & (J) \\
\hline \multirow[t]{4}{*}{5} & 1 & 0 & 1 & 2 & 2 & 0 & 11 & 2,2 \\
\hline & 2 & 0 & 0 & 2 & 2 & 1 & 14 & 2,8 \\
\hline & & 0 & 1 & 4 & 4 & 1 & & 5 \\
\hline & & 0 & 1 & 8 & 12 & 4 & 3 & 2,5 \\
\hline
\end{tabular}

Tabel 7 di atas merupakan rekapitulasi hasil perhitungan heuristik aspek H5 dengan 2 sub aspek heuristik. Nilai severety rating yang dihasilkan sebesar 2,5. 
Tabel 8. Menghitung Evaluasi Heuristik Aspek H6

\begin{tabular}{l|c|c|c|c|c|c|c|c|}
\hline Aspek & Sub Aspek & \multicolumn{5}{|c|}{ SR } & Jumlah & \multirow{2}{*}{ Nilai SR } \\
\cline { 3 - 7 } Heuristik & Heuristik & 0 & 1 & 2 & 3 & 4 & SR & \\
\hline (A) & $(\mathrm{B})$ & $(\mathrm{C})$ & $(\mathrm{D})$ & $(\mathrm{E})$ & $(\mathrm{F})$ & $(\mathrm{G})$ & $(\mathrm{I})$ & $(\mathrm{J})$ \\
\hline 6 & 1 & 0 & 0 & 1 & 3 & 1 & 15 & 3 \\
\hline & 2 & 0 & 0 & 0 & 4 & 1 & 16 & 3,2 \\
\hline & 3 & 0 & 0 & 1 & 3 & 1 & 15 & 3 \\
\hline & & 0 & 0 & 2 & 10 & 3 & & 9,2 \\
\hline & & 0 & 0 & 4 & 30 & 12 & 3 & 3,07 \\
\hline
\end{tabular}
Keterangan :
SR : Severety Rating

Tabel 8 di atas merupakan rekapitulasi hasil perhitungan heuristik aspek H6 dengan 3 sub aspek heuristik. Nilai severety rating yang dihasilkan sebesar 3,07.

Tabel 9. Menghitung Evaluasi Heuristik Aspek H7

\begin{tabular}{|c|c|c|c|c|c|c|c|c|}
\hline \multirow{2}{*}{$\begin{array}{c}\text { Aspek } \\
\text { Heuristik } \\
\end{array}$} & \multirow{2}{*}{$\begin{array}{c}\text { Sub Aspek } \\
\text { Heuristik }\end{array}$} & \multicolumn{5}{|c|}{ SR } & \multirow{2}{*}{$\begin{array}{c}\text { Jumlah } \\
\text { SR }\end{array}$} & \multirow{2}{*}{ Nilai SR } \\
\hline & & 0 & 1 & 2 & 3 & 4 & & \\
\hline (A) & (B) & (C) & (D) & (E) & (F) & (G) & (I) & (J) \\
\hline \multirow[t]{3}{*}{7} & 1 & 0 & 0 & 1 & 3 & 1 & 15 & 3 \\
\hline & & 0 & 0 & 1 & 3 & 1 & & 3 \\
\hline & & 0 & 0 & 2 & 9 & 4 & 3 & 3 \\
\hline
\end{tabular}

Tabel 9 di atas merupakan rekapitulasi hasil perhitungan heuristik aspek $\mathrm{H} 7$ dengan 1 sub aspek heuristik. Nilai severety rating yang dihasilkan sebesar 3 .

Tabel 10. Menghitung Evaluasi Heuristik Aspek H8

\begin{tabular}{|c|c|c|c|c|c|c|c|c|}
\hline \multirow{2}{*}{$\begin{array}{c}\text { Aspek } \\
\text { Heuristik }\end{array}$} & \multirow{2}{*}{$\begin{array}{c}\text { Sub Aspek } \\
\text { Heuristik }\end{array}$} & \multicolumn{5}{|c|}{ SR } & \multirow{2}{*}{$\begin{array}{c}\text { Jumlah } \\
\text { SR }\end{array}$} & \multirow{2}{*}{ Nilai SR } \\
\hline & & 0 & 1 & 2 & 3 & 4 & & \\
\hline (A) & (B) & (C) & (D) & (E) & (F) & (G) & (I) & (J) \\
\hline \multirow[t]{6}{*}{8} & 1 & 0 & 0 & 1 & 3 & 1 & 15 & 3 \\
\hline & 2 & 0 & 0 & 1 & 3 & 1 & 15 & 3 \\
\hline & 3 & 0 & 0 & 2 & 2 & 1 & 14 & 2,8 \\
\hline & 4 & 0 & 0 & 0 & 3 & 2 & 17 & 3,4 \\
\hline & & 0 & 0 & 4 & 11 & 5 & & 12,2 \\
\hline & & 0 & 0 & 8 & 33 & 20 & 3 & 3,05 \\
\hline
\end{tabular}

Tabel 10 di atas merupakan rekapitulasi hasil perhitungan heuristik aspek H8 dengan 4 sub aspek heuristik. Nilai severety rating yang dihasilkan sebesar 3,05.

Tabel 11. Menghitung Evaluasi Heuristik Aspek H9

\begin{tabular}{|c|c|c|c|c|c|c|c|c|}
\hline \multirow{2}{*}{$\begin{array}{c}\text { Aspek } \\
\text { Heuristik }\end{array}$} & \multirow{2}{*}{$\begin{array}{c}\text { Sub Aspek } \\
\text { Heuristik }\end{array}$} & \multicolumn{5}{|c|}{ SR } & \multirow{2}{*}{$\begin{array}{c}\text { Jumlah } \\
\text { SR }\end{array}$} & \multirow{2}{*}{ Nilai SR } \\
\hline & & 0 & 1 & 2 & 3 & 4 & & \\
\hline (A) & (B) & (C) & (D) & (E) & (F) & (G) & (I) & (J) \\
\hline 9 & 1 & 0 & 0 & 1 & 3 & 1 & 15 & 3 \\
\hline & 2 & 0 & 0 & 1 & 3 & 1 & 15 & 3 \\
\hline & & 0 & 0 & 2 & 6 & 2 & & 6 \\
\hline & & 0 & 0 & 4 & 18 & 8 & 3 & 3 \\
\hline
\end{tabular}

Tabel 11 di atas merupakan rekapitulasi hasil perhitungan heuristik aspek $\mathrm{H} 9$ dengan 2 sub aspek heuristik. Nilai severety rating yang dihasilkan sebesar 3 .

Tabel 12. Menghitung Evaluasi Heuristik Aspek H10

\begin{tabular}{|c|c|c|c|c|c|c|c|c|}
\hline \multirow{2}{*}{$\begin{array}{c}\text { Aspek } \\
\text { Heuristik }\end{array}$} & \multirow{2}{*}{$\begin{array}{c}\text { Sub Aspek } \\
\text { Heuristik }\end{array}$} & \multicolumn{5}{|c|}{ SR } & \multirow{2}{*}{$\begin{array}{c}\text { Jumlah } \\
\text { SR }\end{array}$} & \multirow{2}{*}{ Nilai SR } \\
\hline & & 0 & 1 & 2 & 3 & 4 & & \\
\hline (A) & (B) & (C) & (D) & (E) & (F) & (G) & (I) & (J) \\
\hline \multirow[t]{4}{*}{10} & 1 & 0 & 0 & 1 & 3 & 1 & 15 & 3 \\
\hline & 2 & 0 & 0 & 1 & 3 & 1 & 15 & 3 \\
\hline & & 0 & 0 & 2 & 6 & 2 & & 6 \\
\hline & & 0 & 0 & 4 & 18 & 8 & 3 & 3 \\
\hline
\end{tabular}

Tabel 12 di atas merupakan rekapitulasi hasil perhitungan heuristik aspek $\mathrm{H} 10$ dengan 2 sub aspek heuristik. Nilai severety rating yang dihasilkan sebesar 3 .

Daftar nilai SR (severety rating) pada kolom C,D,E,F,F merupakan nilai dari evaluasi heuristik. Sedangkan untuk kolom I merupakan kolom yang berisi jumlah severety rating yang diperoleh dari penjumlahan nilai severety rating. Berdasarkan persamaan 1 bahwa:

$\mathrm{I}=(0 * \mathrm{C} 1)+(1 * \mathrm{D} 1)+(2 * \mathrm{E} 1)+(3 * \mathrm{~F} 1)+$ $(4 * \mathrm{G} 1)$

Untuk kolom $\mathbf{J}$ merupakan nilai severety rating yang diperoleh dengan melakukan pembagian pada kolom $\mathrm{J}=\mathrm{I} / 4$.

Tabel 4. Rekapitulasi Nilai Severery Rating Website Kuliah Online STMIK Amikom Purwokerto

\begin{tabular}{|c|c|c|}
\hline Aspek Heuristik & $\begin{array}{c}\text { Nilai Rata-Rata } \\
\text { Severety } \\
\text { Rating }\end{array}$ & $\begin{array}{c}\text { Nilai } \\
\text { Pembulatan } \\
\text { Skala } 0-4\end{array}$ \\
\hline 1 & 3,13 & 3 \\
\hline 2 & 3,1 & 3 \\
\hline 3 & 2,7 & 3 \\
\hline 4 & 3,1 & 3 \\
\hline 5 & 2,5 & 3 \\
\hline 6 & 3,07 & 3 \\
\hline 7 & 3 & 3 \\
\hline 8 & 3,05 & 3 \\
\hline 9 & 3 & 3 \\
\hline 10 & 3 & 3 \\
\hline $\begin{array}{c}\text { Nilai Rata-Rata } \\
\text { Severety Rating }\end{array}$ & 2,96 & 3 \\
\hline
\end{tabular}

Hasil uji menggunakan evaluasi heuristik secara keseluruhan ditunjukkan seperti pada tabel 3 sampai tabel 12. Nilai severety rating menunjukkan seberapa besar tingkat usability pada website kuliah online STMIK Amikom Purwokerto. Berdasarkan hasil evaluasi 
heuristik pada tabel 13 memiliki nilai rata-rata severety rating sebesar 2,96 atau skala 3 . Hal ini menunjukkan bahwa website kuliah online STMIK Amikom Purwokerto perlu ada perbaikan.

\section{SIMPULAN DAN SARAN}

Dari penelitian yang telah dilakukan dapat diambil kesimpulan, secara keseluruhan nilai rata-rata dari semua aspek pada perhitungan heuristik bernilai 2,96 atau dibulatkan menjadi skala 3 yang berarti website kuliah online perlu untuk melakukan perbaikan baik dari fungsionalitas sistem maupun desain antarmuka.

Dengan memperhatikan hasil penelitian maka dapat diberikan saran untuk penelitian ini, antara lain:

1. Hasil pengujian dari perhitungan evaluasi heuristik digunakan sebagai saran untuk perbaikan website kuliah online STMIK Amikom Purwokerto dengan harapan agar sesuai dengan prinsip usability.

2. Untuk peneliti selanjutnya, dapat dilakukan evaluasi menggunakan metode lain atau mengembangkan dari evaluasi yang sudah ada seperti membandingkan efektitifitas antara kuliah tatap muka dan kuliah secara online menggunakan metode POST Questionaire.

\section{UCAPAN TERIMA KASIH}

Peneliti mengucapkan terima kasih kepada semua pihak yang telah mendukung dalam menyelesaikan penelitian ini dalam bentuk waktu, motivasi, dan juga pengetahuan.

\section{REFERENSI}

[1] U.-U. N. 12 T. 2012, "Undang-Undang Republik Indonesia Nomor 12 Tahun 2012 Tentang Pendidikan Tinggi,” 2016.

[Online]. Available: http://sumberdaya.ristekdikti.go.id/wpcontent/uploads/2016/02/uu-nomor-12tahun-2012-ttg-pendidikan-tinggi.pdf. [Accessed: 09-Feb-2019].

[2] A. Pane and M. D. Dasopang, "Belajar dan Pembelajaran," J. Kaji. Ilmu-ilmu Keislam., vol. 3, no. 2, pp. 333-352, 2017.

[3] A. Purnomo, N. Ratnawati, and N. F. Aristin, "Pengembangan Pembelajaran Blended Learning Pada Generasi Z," J. Teor. dan Praksis Pembelajaran IPS, vol. 1, no. 1, pp. 70-76, 2018.

[4] V. Sahfitri and M. Ulfa, "Evaluasi Usability Sistem E-Learning Sebagai Aplikasi Pendukung Proses Pembelajaran Di Perguruan Tinggi Menggunakan Use Questionnaire," Ilm. MATRIK, vol. 17 No.1, pp. 53-66, 2015.

[5] S. Bibi and H. Jati, "Efektivitas Model Blended Learning Terhadap Motivasi dan Tingkat Pemahaman Mahasiswa Mata Kuliah Algoritma dan Pemrograman," J. Pendidik. Vokasi, vol. 5, no. 1, pp. 74-87, 2015.

[6] Y. Yuberti, “Online Group Discussion pada Mata Kuliah Teknologi Pembelajaran Fisika," J. Ilm. Pendidik. Fis. Al-Biruni, vol. 4, no. 2, p. 145, 2017.

[7] A. Qashlim, T. Prahasto, and R. Gernowo, "Evaluasi Human Machine Interface Menggunakan Kriteria Usability Pada Sistem E-learning Perguruan Tinggi," J. Sist. Inf. Bisnis, vol. 4, no. 2, pp. 96-107, 2016.

[8] T. Lestariningsih, "Analisis Sitem Informasi Dalam Perspektif Human Computer Interaction," J. AKSI (Akuntansi dan Sist. Informasi), vol. 1, no. 1, pp. 5-9, 2018.

[9] A. Ali and E. W. Faida, "Evaluasi Heuristik Pada Web Based Learning Dalam Upaya Meningkatkan Kemudahan Pengisian Try Out Uji Kompetensi Bagi Mahasiswa D3 RMIK STIKES Yayasan RS Dr.Soetomo," Manaj. Kesehat. STIKES Yayasan RS. Dr. Soetomo, vol. 2, no. 1, pp. 74-80, 2016.

[10] A. Ali, E. Pramana, and S. Tjandra, "Evaluasi Heuristik Pada Web Based Learning Untuk Meningkatkan Aspek Usability Sistem," Insa. Comtech, vol. 1, no. 1, pp. 17-25, 2016.

[11] E. Iryanti, "Evaluasi User Interface Video Interaktif Manusia Purba dengan Menggunakan Metode Heuristik," $J$. INFOTEL - Inform. Telekomun. Elektron., vol. 6, no. 2, p. 89, 2016.

[12] Sugiyono, Metode Penelitian \& Pengembangan. 2015: Penerbit Alfabeta, 2015.

[13] D. R. Rahadi, "Pengukuran Usability Sistem Menggunakan Use Questionnaire Pada Aplikasi Android," J. Sist. Inf., vol. 
6, no. 1, pp. 661-671, 2014.

[14] M. Sulistiyono, "EVALUASI

HEURISTIC SISTEM INFORMASI

PELAPORAN KERUSAKAN

LABORATORIUM UNIVERSITAS

AMIKOM YOGYAKARTA," $J$. Ilm. Data Manaj. dan Teknol. Inf., vol. 18, no. 1, pp. 37-43, 2017.

[15] Andi Wahju Rahardjo Emanuel, Petunjuk Praktis Metode Penelitian Teknologi Informasi. Yogyakarta: Penerbit ANDI, 2017. 